\title{
An audit of the decision to delivery interval in emergency caesarean section and its effect on neonatal outcome
}

\author{
Anuradha G.*, Nirupama V., Shirley George
}

Department of Obstetrics and Gynaecology, St. John's Medical College and Research Institute, Bangalore, Karnataka, India

Received: 02 August 2020

Revised: 09 September 2020

Accepted: 10 September 2020

\section{*Correspondence:}

Dr. Anuradha G.,

E-mail: anumahesh2009@gmail.com

Copyright: () the author(s), publisher and licensee Medip Academy. This is an open-access article distributed under the terms of the Creative Commons Attribution Non-Commercial License, which permits unrestricted non-commercial use, distribution, and reproduction in any medium, provided the original work is properly cited.

\section{ABSTRACT}

Background: Emergency caesarean section (CS) is divided into four categories based on the degree of urgency by RCOG and NICE guidelines. It is recommended that the decision to delivery interval (DDI) in emergency CS should be within 30 minutes in category 1 and within 75 minutes in category 2. Our Primary objective was to study the incidence and indications of emergency CS and audit the DDI in emergency CS at tertiary care hospital. Our secondary objective was to study the effect of DDI on neonatal outcome.

Methods: Descriptive study was carried out among 409 women who underwent emergency CS from August 2018 to December 2018 at St. John's medical college hospital, Bangalore. Relevant data was collected by chart review. Emergency CS were categorised according to RCOG guidelines based on the degree of urgency and further classified based on DDI as <30 minutes, 30-75 minutes and >75 minutes.

Results: We had 409 cases of emergency CS. Category 1 had $113(27.63 \%)$ cases, category 2 had $126(30.81 \%)$ cases and category 3 had $170(41.56 \%)$ cases. DDI of $<30$ minutes was achieved in $19.5 \%$ in category 1 , DDI of <75 minutes was achieved in $93.65 \%$ in category 2 . Fetal distress was the leading cause of emergency CS in category 1 and 2. There was a high incidence of low APGAR in babies delivered in $<30$ minutes and lower APGAR was significantly associated with $<30$ minutes of DDI $(\mathrm{p}<0.0001)$.

Conclusions: Fetal distress was the leading cause of emergency CS. DDI interval of <30 minutes was not always associated with good neonatal outcome; Category of CS has a significant effect on neonatal outcome.

Keywords: Decision to delivery interval, Emergency CS, NICE, RCOG

\section{INTRODUCTION}

The caesarean section (CS) is traditionally classified into elective and emergency. As some emergency caesarean sections are clearly more urgent than others this broad classification limits its usefulness in terms of data comparison at local, national or international level. Also, the degree of urgency in a particular case has to be understood by different teams involved like the obstetric, anaesthetic and nursing teams to provide the required care for maternal and fetal well-being.
Lucas et al in 2000 conducted a study with obstetricians and anaesthetists to grade urgency of CS. ${ }^{1}$ They proposed a classification of $\mathrm{CS}$ based on clinical definition of urgency into four grades. RCOG introduced the concept that urgency of CS represents a continuum of risk. ${ }^{2}$ They added a colour spectrum to the four broad categories proposed by Lucas to emphasize continuum of risk. A coloured spectrum signifies that within each category the degree of risk in an individual case can vary and suggested that a case requires an individual approach in deciding the specific DDI. However, for audit purposes four defined categories is useful. According to RCOG 
and NICE guidelines (2011) caesarean section is divided into four categories based on the degree of urgency. ${ }^{2,3}$

Category 1: Immediate threat to the life of women or fetus Category 2: Maternal or fetal compromise that is not immediately life-threatening Category 3: Needing early delivery but no maternal or fetal compromise Category 4: At a time to suit the women and maternity team.

RCOG and NICE guidelines recommend a decision to delivery interval (DDI) of less than 30 minutes for category 1 and DDI of less than 75 minutes for category $2 .^{3}$ This guideline is useful for clinical audit of quality and efficiency of the obstetric team and hospital. ${ }^{2,3}$

The origin of the 30-minute rule was in 1988 when USA did a nationwide survey and showed that almost all hospitals had the ability to carry out an emergency CS within 30 minutes. ${ }^{4}$ This rule was subsequently adopted by ACOG, American Academy of Paediatrics and other professional bodies like the Clinical negligence scheme for trusts and confidential Enquiry into Stillbirths and Deaths in Infancy (CESDI). ${ }^{5-7}$

The 30 minute rule should be seen as a 'capability' of the hospital in an emergency situation and not as a requirement. ${ }^{8}$ The scientific rationale of 30 minute rule is a consensus of experts and is not supported by clinical trials. ${ }^{9}$ It has also been observed that rapid delivery may increase the risk of maternal morbidity and was not always associated with improved neonatal outcome..$^{2,10}$

The Primary Objective of this study was to determine the incidence of emergency CS in each category and to audit the decision to delivery interval in each category of emergency CS. The Secondary Objective was to study the effect of DDI on neonatal outcomes.

\section{METHODS}

It is a descriptive study done at St. John's Medical College and Hospital from the period of August 2018 to December 2018. Inclusion criteria- All cases of emergency caesarean section during the study period. Exclusion criteria- All elective caesarean sections.

All the cases who underwent CS during this period were noted from the parturition register. The charts of these cases were obtained from the medical records department. Relevant data was noted like the age, parity index, gestational age (GA), DDI, indication for CS, CTG and APGAR score at 5 minutes. According to the indication, caesarean sections were categorized into category 1, 2, 3 and 4 based on degree of urgency (RCOG and NICE guidelines). Elective caesarean sections (category 4) was excluded from the study. The DDI for each case of emergency caesarean section was noted under 3 categories i.e. $<30$ minutes, 30-75 minutes and $>75$ minutes. The data was put in tables showing the distribution of indication by decision to delivery interval for each category. Clearance and approval from the institutional ethical and research committee was obtained.

\section{Statistical methods}

Descriptive statistics were reported as number and percentages. Chi square test was used to test the association between the study variables. $P$ value less than $0.05 \%$ was considered as statistically significant. Data was entered in MS Excel and analysis was performed using SPSS version 25.0.

\section{RESULTS}

Total number of deliveries during the study period August 2018 to December 2018 was 1228 . The CS rate was $43.48 \%$ (534) of which emergency CS was $33.30 \%$ (409) and elective CS was $10.17 \%$ (125). Four hundred and nine (409) (n) women were categorized according to RCOG and NICE guidelines and audited for DDI. Among 409 women, 113 (27.6\%) belonged to category I, $126(30.8 \%)$ and $170(41.6 \%)$ belonged to category II and III respectively. Nearly $90 \%$ of the women were in the age group 20-35 years and $61 \%$ were primipara. In our study $20.78 \%$ of the pregnant women were in the GA>40 weeks and $6.85 \%$ were in the GA<32 weeks (Figure 1-3).

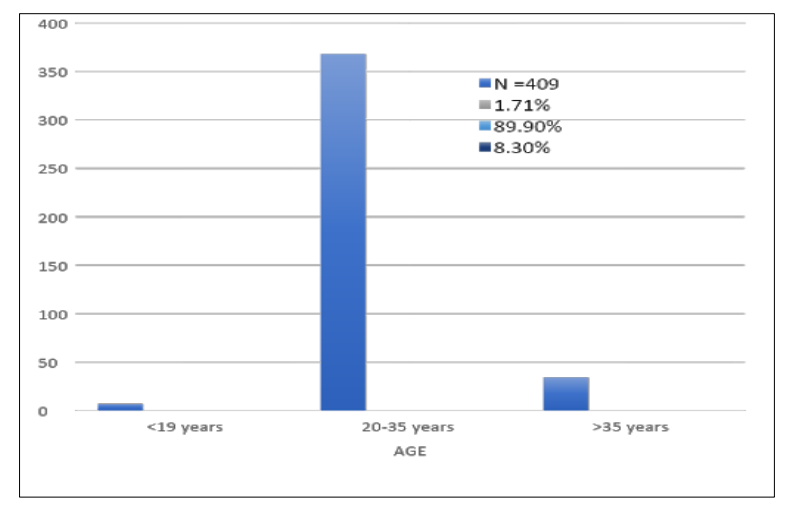

Figure 1: Distribution by age.

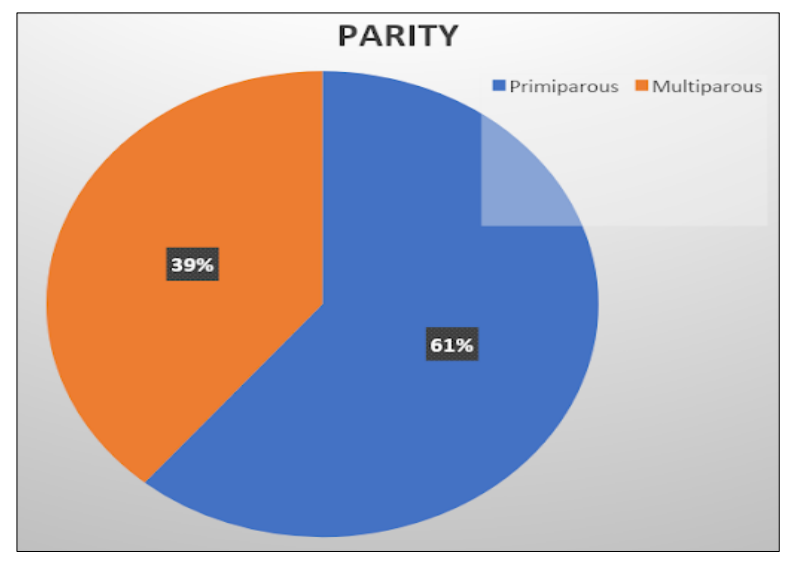

Figure 2: Distribution by parity. 


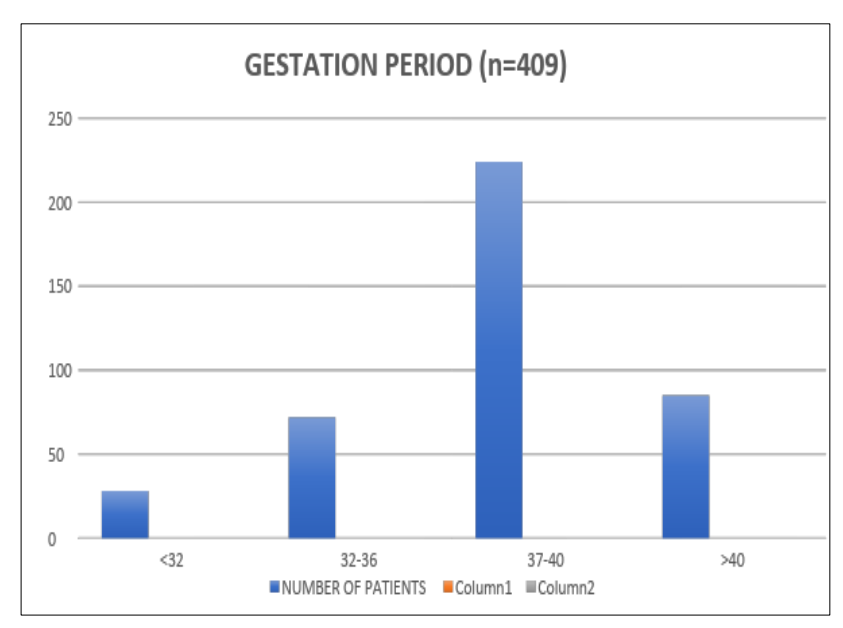

Figure 3: Distribution by gestational age.

Category I was cases where there was immediate threat to the life of women or fetus. Hence recommended DDI is
$<30$ minutes. Among 113 cases, it was observed that $19.5 \%, 74.3 \%$ and $6.2 \%$ had delivered in $<30$ mins, $30-75$ mins and $>75$ min's respectively. Out of the 113 cases in category 1 only $22(19.5 \%)$ could be delivered in the recommended DDI of <30 minutes (Table 1).

Maximum were fetal distress $85(75.2 \%)$ cases detected by variable and late decelerations of which only 13 could be delivered within 30 minutes of decision to delivery; there was 7 severe abruption cases of which 4 could be delivered within 30 minutes and 1 case of cord prolapse that was delivered within 30 minutes (Table 1).

In category 2 there were $126(30.81 \%)$ cases. This category included cases where there was maternal or fetal compromise which is not immediately life threatening. Hence recommended DDI is within 75 minutes. Out of 126 cases in category 2 only in $6.35 \%$ we could not achieve the recommended DDI and 118 (93.65\%) were delivered within 75 minutes (Table 2).

Table 1: Analysis of indications of CS and DDI in category 1.

\begin{tabular}{|c|c|c|c|c|}
\hline Category 1 & DDI & & & \\
\hline Indication & $<30 \min N(\%)$ & $30-75 \min N(\%)$ & $>75 \min N(\%)$ & Total N (\%) \\
\hline Cord prolapse & $1(4.5)$ & 0 & 0 & $1(0.88)$ \\
\hline Severe abruption (grade 2-3) & $4(18.2)$ & $3(3.6)$ & 0 & $7(6.19)$ \\
\hline Decelerations (variable and late) & $13(59.1)$ & $65(77.3)$ & $7(100)$ & $85(75.2)$ \\
\hline Placenta previa with shock & $1(4.5)$ & $3(3.6)$ & 0 & $4(3.5)$ \\
\hline Uterine rupture & 0 & 0 & 0 & 0 \\
\hline Scar dehiscence & $3(13.6)$ & $4(4.8)$ & 0 & $7(6.2)$ \\
\hline Failed instrumentation & 0 & 0 & 0 & 0 \\
\hline 2nd stage CS & 0 & $9(10.7)$ & 0 & $9(7.9)$ \\
\hline Total & 22 & 84 & 7 & 113 \\
\hline
\end{tabular}

Table 2: Analysis of indications of CS and DDI in category 2.

\begin{tabular}{|c|c|c|c|c|}
\hline Category 2 & DDI & & & \\
\hline Indication & $<30 \min N(\%)$ & $30-75 \min N(\%)$ & $>75 \min N(\%)$ & Total N (\%) \\
\hline Non-reassuring CTG & 0 & $57(51.4)$ & $4(50)$ & $61(48.4)$ \\
\hline Grade 1 abruption & 0 & $1(0.90)$ & 0 & $1(0.79)$ \\
\hline MSL & $1(14.3)$ & $29(26.1)$ & $1(12.5)$ & $31(24.6)$ \\
\hline Malpresentation in active labour & $3(42.8)$ & $7(6.30)$ & 0 & $10(7.94)$ \\
\hline Placenta previa without shock & 0 & $2(1.80)$ & 0 & $2(1.58)$ \\
\hline Obstructed labour & 0 & 0 & 0 & 0 \\
\hline Eclampsia & $2(28.6)$ & $2(1.80)$ & 0 & $4(3.17)$ \\
\hline Labour dystocia (arrest of descent & $1(14.3)$ & $13(11.7)$ & $3(37.5)$ & $17(13.5)$ \\
\hline Total & 7 & 111 & 8 & 126 \\
\hline
\end{tabular}

Maximum CS in this category was for non - reassuring CTG that was $61(48.4 \%)$ cases of which in 57 cases DDI was between 30- 75 minutes; MSL was 31 (24.6\%) of which only 1 delivered beyond 75 minutes of decision; labour dystocia was in $17(13.5 \%)$ and 3 delivered beyond 75 minutes (Table 2 ).

In category 3 as there is no maternal or fetal compromise there is no defined time for DDI. There were 170 $(41.56 \%)$ cases in this category. Out of 170 cases in category $3 ; 150(88 \%)$ delivered within 75 minutes and $12 \%$ were delivered beyond 75 minutes. Majority were previous CS in early labour with 44 (25.9\%) cases followed by CPD $31(18.2 \%)$ and worsening maternal condition (severe PE) 24 (14.1\%) cases (Table 3).

The relationship between fetal outcome and DDI was studied by taking the APGAR at 5 minutes. Neonates with APGAR $<7$ and $>7$ in each delivery interval was noted. Out of 409 neonates 85 neonates had APGAR $<7$ 
(Table 4). Out of 409 neonates 31 were delivered in $<30$ minutes and $20(64.5 \%)$ of these neonates had APGAR $<7$ which was significantly associated $(\mathrm{p}<0.0001)$ (Table 4). The reason for low APGAR was further analysed by looking at the association of category of CS to DDI (Table 5). Hence the 85 neonates with low APGAR were analysed according to their category. We had maximum neonates in category 3 (34) followed by category 1 (32) and category 2 (19). In <30 minutes 20 neonates were delivered with $13(65 \%)$ belonging to category 1 which was statistically significant $(\mathrm{p}=0.046)$. Hence low APGAR was associated with the category of CS. We had 34 neonates with low APGAR in category 3 out of which 33 were delivered within 75 minutes.

Table 3: Analysis of indications of CS and DDI in category 3.

\begin{tabular}{|c|c|c|c|c|}
\hline Category 3 & DDI & & & \\
\hline Indication & $<30 \min N(\%)$ & $30-75 \min N(\%)$ & $>75 \min N(\%)$ & Total N (\%) \\
\hline CPD & 0 & $31(20.9)$ & 0 & $31(18.2)$ \\
\hline Failed induction of labour & 0 & $16(10.8)$ & $6(30.0)$ & $22(12.9)$ \\
\hline Previous CS in early labour & 0 & $37(25)$ & $7(35.0)$ & $44(25.9)$ \\
\hline Malpresentation in latent labour & 0 & $13(8.78)$ & $1(5.0)$ & $14(8.23)$ \\
\hline Planned elective CS in labour & 0 & $18(12.2)$ & $1(5.0)$ & $19(11.20)$ \\
\hline $\begin{array}{l}\text { Doppler changes (AEDF/CPR } \\
\text { reversal) }\end{array}$ & 0 & $13(8.78)$ & $3(15.0)$ & $16(9.41)$ \\
\hline Worsening maternal condition (PE) & $2(100)$ & $20(13.5)$ & $2(10.0)$ & $24(14.1)$ \\
\hline Total & 2 & 148 & 20 & 170 \\
\hline
\end{tabular}

Table 4: Relationship between APGAR and DDI.

\begin{tabular}{|llllll|}
\hline APGAR at $\mathbf{5}$ min & $<\mathbf{3 0} \min \mathbf{N}(\%)$ & $\mathbf{3 0 - 7 5} \min \mathbf{N}(\%)$ & $\mathbf{> 7 5} \min \mathbf{N}(\%)$ & Total $\mathbf{N}(\%)$ & P value \\
\hline$<7$ & $20(64.5 \%)$ & $62(18.1)$ & $3(8.6 \%)$ & 85 & $<0.0001$ \\
\hline$>\mathbf{7}$ & $11(35.5 \%)$ & $281(81.9 \%)$ & $32(91.4 \%)$ & 324 & \\
\hline Total & 31 & 343 & 35 & 409 \\
\hline
\end{tabular}

Table 5: Association of category of CS to DDI (APGAR<7).

\begin{tabular}{|c|c|c|c|c|c|}
\hline APGAR $<7$ & $<30 \min \mathbf{N}(\%)$ & $30-75 \min \mathbf{N}(\%)$ & $>75 \min N(\%)$ & Total & P value \\
\hline Category 1 & $13(65)$ & $18(29)$ & $1(33.3)$ & 32 & \multirow{3}{*}{0.046} \\
\hline Category 2 & $4(20)$ & $14(23)$ & $1(33.3)$ & 19 & \\
\hline Category 3 & $3(15)$ & $30(48.4)$ & $1(33.3)$ & 34 & \\
\hline Total & 20 & 62 & 3 & 85 & \\
\hline
\end{tabular}

\section{DISCUSSION}

The quality of maternity care can be measured by monitoring the capability of the maternity unit to respond to urgent situations. DDI is an important measure of assessing the quality of maternity care. ${ }^{10}$ Hence it is important to carry out regular audits of DDI., ${ }^{2,7}$ Audit at our hospital showed that the majority of our emergency CS were delivered within 75 minutes irrespective of the category.

The percentage of cases in category 1 and 2 and the commonest indication for emergency $\mathrm{CS}$ in these categories was comparable to the study done by Thool et al. ${ }^{11}$ We could deliver $19.5 \%$ of category 1 within 30 minutes which was comparable to that of a study done in a tertiary care hospital in Thailand. ${ }^{12}$

We realised that we need to improve the efficiency of our team in category $1 \mathrm{CS}$. In our hospital we do not categorise CS based on urgency as a standard practise. Adopting the NICE guidelines and categorizing based on urgency may help us to improve our efficiency by sensitising the Obstetric, Anaesthesia and Nursing teams.

Many studies were conducted to assess if the 30 minute rule is achievable in real practice. Tuffnell et al conducted 4 audit cycles on DDI in urgent CS and found that with each audit cycle they could achieve improvement in the DDI. ${ }^{13}$ Helmy $\mathrm{WH}$ et al reported improvement in achieving DDI within 30 minutes after introduction of a structured time sheet for recording decisions and actions. ${ }^{14}$ Most important is to recognise and select category $1 .^{15}$ Teamwork and communication will help to achieve the recommended DDI.

Since it is retrospective study we do not have the data for the time taken to shift to the operation theatre, anaesthesia time and incision to delivery time.

Our results showed that there was a high incidence of APGAR $<7$ in neonates delivered in $<30$ minutes. A retrospective study conducted by Bloom et al showed increased incidence of acidosis in DDI $<30$ minutes 
compared to DDI>30 minutes $(4.8 \% \mathrm{v} / \mathrm{s} 1.6 \%) .{ }^{16}$ Another large study conducted by Thomas et al found no difference in neonatal outcome between $<15$ minutes and 16-75 minutes. However DDI $>75$ minutes had increased odds of low APGAR. ${ }^{17}$

We studied the association of the category of CS with the DDI. There was a higher incidence of low APGAR in category $1 \mathrm{CS}$ in our study. Similar results were shown by Grace et al where higher incidence of APGAR $<7$ at 5 minutes was seen in category 1 compared to non category $1(5.8 \%$ of category $1 \mathrm{v} / \mathrm{s} 1.9 \%$ for non category 1$) .{ }^{18}$ Most of the category $1 \mathrm{CS}$ was for non-reassuring fetal status in their study which was also seen in our study.

Researchers have tried to explain the poor outcome in category 1 in spite of achieving recommended DDI. Cases like cord prolapse, abruption, scar rupture have higher risk of fetal hypoxia and the whole team of obstetricians and anaesthetists are fast in their action. The cause of fetal distress is irreversible in these conditions opposed to fetal distress in potentially reversible conditions like uterine hyperstimulation, epidural anaesthesia and aortocaval compression. ${ }^{2,15}$ So, there can be failure to demonstrate a temporal relation between adverse outcome and DDI. ${ }^{2}$

Fetal distress in most studies including our study is based on CTG which has high sensitivity and poor specificity for fetal hypoxia. ${ }^{19,20}$ Fetal distress diagnosed by CTG was the leading cause of emergency CS in category 1 and 2 in our study that was similar to other studies.

Our study had a higher incidence of low APGAR in category 3 though majority were delivered in 75 minutes of decision. The reason could be the higher number of chronic fetal distress and pre eclampsia cases in this category.

\section{CONCLUSION}

RCOG and NICE guidelines help to classify emergency CS based on degree of urgency and have a time frame for delivering the baby. Obstetricians should adopt the NICE classification of emergency CS. It helps to identify cases requiring immediate delivery. Maternity units should acquire the capability to expedite the delivery in catastrophic and irreversible situations like cord prolapse, severe abruptio and rupture uterus. This is possible by training the nursing and supportive staff and effective communication within the obstetric team and with anaesthesia team. Regular audits for DDI helps to improve the quality of care and sensitise the team towards emergency situations.

\section{ACKNOWLEDGMENTS}

Authors would like to thank Dr. Annamma Thomas (Head of Department of OBG) and statistician Sumithra for their support during the study.
Funding: No funding sources

Conflict of interest: None declared

Ethical approval: The study was approved by the Institutional Ethics Committee

\section{REFERENCES}

1. Lucas DN, Yentis SM, Kinsella SM. Urgency of caesarean section: a new classification. J R Soc Med. 2000;93:346-50.

2. Royal college of Obstetricians \& Gynaecologists, the Royal college of anaesthetists. Classification of urgency of caesarean section - a continuum of risk (good Practise No. 11) Available at: https://www.rcog.org.uk/globalassets/documents/gui delines/good practise no.11 classification of urgency.pdf. Accessed on 17 September 2018

3. National institute for Health and clinical Excellence. CG 132 caesarean Section. Clinical Guidelines for Emergency CS. Available from: http://www.guidence.nice.org.uk. Accessed on 17 September 2018

4. American college of Obstetricians and gynaecologists standards for obstetric services, 6th edition, ACOG, Washington, DC, 1988.

5. American Academy of Paediatrics and American college of Obstetricians and Gynaecologist. Guidelines for perinatal care, 2nd edition, The college, Washington, DC, 1988.

6. Clinical Negligence scheme for Trusts Clinical risk management standards London, UK, 1999 criterion $12 ; 3 ; 1$.

7. CESDI confidential enquiry into stillbirths and deaths in infancy: 7th annual report Maternal and Child Health Research Consortium, London, 2000;41-52.

8. American Academy of Paediatrics, American college of Obstetricians and Gynaecologists guidelines for perinatal care (5th edition), ACOG, Elk Grove village(IL): AAP; Washington, DC 2002;147.

9. Schauberger $\mathrm{CW}$, Chauhan SP. Emergency caesarean section $\&$ the 30 - minute rule: definitions Am j Perinatol 2009;26:221-6.

10. Thomas J, Paranjothy S, James D. National cross sectional survey to determine whether the decision to delivery interval is critical in emergency caesarean section. BMJ 2004;328:665-9.

11. Thool KN, Jain SM, Shivkumar PV, Jain MA, Podder MR. A clinical audit and confidential enquiry of caesarean section indications at rural tertiary health care centre. Int J Reprod Contracept Obstet Gynecol 2017;14-3.

12. Khemworapong K, Sompagdee N, Boriboonhirunsarn D. DDI in emergency caesarean section in tertiary care hospital in Thailand Obstet Gynecol Sci V. 2018;61(1):48-55.

13. Tuffnell DJ, Wilkinson K, Beresford N. Interval between decision and delivery by caesarean sectionare current standards achievable? Observational case series BMJ 2001;322:1330-3. 
14. Helmy WH, Jolaoso AS, Ifaturoti OO, Afify SA, Jones $\mathrm{MH}$. The decision to delivery interval for emergency caesarean section: Is 30 - minutes rule a realistic target? BJOG 2002;109:505-8.

15. Leung TY, Chung PW, Rogers MS, et al. Urgent caesarean delivery for fetal bradycardia. Obstet Gynecol 2009;114:1023-8.

16. Bloom SL, Leveno KJ, Spong CY. National institute of child health and Human development. Maternal Fetal Medicine units network. Decision to incision times and infant outcomes. Obstet Gynecol 2006;108:6-11.

17. Thomas J, Paranjothy S, James D, National cross sectional survey to determine whether the decision to delivery interval is critical in emergency caesarean section. BMJ 2004;328:665-7.
18. Grace L, Greer MR, Kumar S. Perinatal consequences of a category 1 caesarean section at term. BMJ open 2015;7:5.

19. Nelson KB, Dambrosia JM, Ting TY. Uncertain value of electronic fetal monitoring in predicting cerebral palsy. N Engl J Med 1996;334:613-8.

20. Roy KK, Baruah J, Kumar S, Deorari AK, Sharma JB, Karmakar D. Caesarean section for suspected fetal distress, continuous fetal heart monitoring and decision to delivery time. Indian $\mathrm{J}$ Pediatrics 2008;75:1249-52.

Cite this article as: Anuradha G, Nirupama V, George S. An audit of the decision to delivery interval in emergency caesarean section and its effect on neonatal outcome. Int J Reprod Contracept Obstet Gynecol 2020;9:4202-7. 